\title{
Feasibility and Utilization of GFRP in Concrete Structures
}

\author{
Ankit Raj Sinha ${ }^{1}$, Sanjay Prakash ${ }^{1}$, Khushwant Singh ${ }^{1}$, Saurabh Kumar ${ }^{1}$, Chandan $_{\text {Kumar }}{ }^{2}$ \\ ${ }^{1}$ UG Student, Dept of Civil Engineering, NSIT Bihta, Patna (India). \\ ${ }^{2}$ Assistant Professor, Dept of Civil Engineering, NSIT Bihta, Patna (India).
}

\begin{abstract}
To meet the needs of modern infrastructure, new innovative materials and technologies have started their way in the construction industry. Any technology or material has its limitations with structures became older and with increasing bar corrosion, older buildings began to demand extra retrofits to increase their durability and life. Recent studies suggest that glass fibers may help replace cement in the concrete industry. Glass fiber has very good cementious properties, so they can be used as an alternative to cement. Cement production with large amounts of carbon dioxide gas is not good for the environment, so replacing cement with glass fibers has a positive effect on the environment. Now the glass industry is facing a problem related to glass waste. This study is beneficial to both industries. Traditional steel bars used in RCC jobs are slowly being replaced with glass fiber reinforced polymer (GFRP) bar. This large change in construction training is due to the high strength, corrosion resistance, durability and good visibility of conventional steel rods in proportion to the weight of the GRRP. However, due to the linear stress strain behavior of GFRP, they are prone to sudden and brittle failures, thereby strengthening the fiber to provide structural protection. In the present study, a review was conducted to discuss aspects of the GFRP bars in RC members.
\end{abstract}

Keywords- GFRP bars, Conventional Cement members, Retrofits, Strength and Properties.

\section{INTRODUCTION}

In today's fast-paced economy, infrastructure development is accelerating. Many concrete and sculptures (Masonry) worldwide is constructed with there is a great market for repairing and replacing these structures for the safe use and enhancing its life span. Lack of strength, stiffness, ductility and durability are the many conditions under which civil construction needs to be strengthened or rehabilitated. Concrete has become possible for each of our new structures and its invention has changed the global construction technology of concrete and rapid marking, so it is important to test important properties of concrete such as compressive strength. The main structure of concrete is cement and the manufacturing process is long, which is not environmentally friendly and harsh, and releases some greenhouse gases such as CO2 and other pollutants, but cement cannot be replaced with other materials for the production of concrete, so the work is partly replacement by silica fume, fly ash and husk. Various research activities need to be carried out to justify replacing cement with other pozzolanic materials.

Here are some common conditions that need to be strengthened for enhancing the life of structure: Code seismic retrofit to meet current code requirements, Upgraded loading requirements; Damage caused by accidents and environmental conditions, Design errors in initial design. Depending on the required characteristics of the structural members, their use and the level of damage they can be repaired and strengthened in a number of widely used ways.

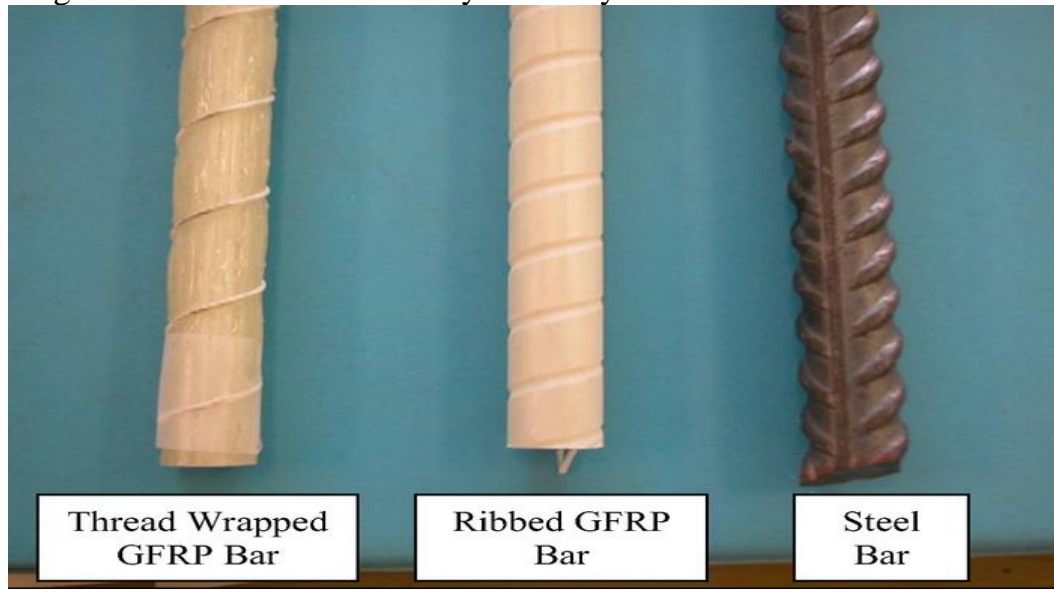

Fig 1 - Types of bond in GFRP bars in comparison with Steel bars

\section{COMPOSITE MATERIALS USED IN REINFORCED STRUCTURES}

FRP alloys and bars are formed by the addition of continuous fiber to the resin alloy. It determines the various control properties of fiber composites and bars.

The most popular fibers used to make carbon fiber, glass fiber and aramid fiber composites and bars. The final products and polymers are made with carbon-fiber reinforced polymer (CFRP), glass-fiber reinforced polymer (GFRP, and aramid-fiber reinforced polymer (ARFP)). 
The non- metallic fibrous origin, these bars differ from their metallic luminosity in that they have linear elastic properties up to failure, high strength to specific gravity, weight and ratio, high corrosion resistance, especially in high corrosive environments and electromagnetic transparency.

Once built, these bars look like epoxy coated steel bars. FRP bars are made of steel rods of all standard sizes and strengths, although they have different guides and their high strength and weight ratio are well documented. Table 1 (Meuer U., 1995) compares these fibers qualitatively.

\begin{tabular}{|c|c|c|c|}
\hline Criterion & \multicolumn{3}{|c|}{ Composite Fiber Made Up of } \\
\hline Tension & Carbon Fibers & Aramid Fibers & E-Glass Fibers \\
\hline Compression & Very Good & Very Good & Gery Good \\
\hline Young's Modulus & Very Good & Inadequate & Adequate \\
\hline Long Term Behavior & Very Good & Good & Adequate \\
\hline Fatigue & Very Good & Good & Adequate \\
\hline Bulk Density & Excellent & Excellent & Adequate \\
\hline Alkaline Resistance & Good & Good & Inadequate \\
\hline Price & Very Good & Adequate & Very Good \\
\hline
\end{tabular}

Table 1- Qualitative comparison between different Fibers (Meuer U., 1995).

\section{UTILITY AND ITS LIMITATION}

GFRP is very capable and has advantages compared to traditional materials and technologies in retrofitting of RC structures. Increase in GFRP usage They may cause retrofitting of the RC structure in qualitative advantages, which are mainly - corrosion resistance, light weight, very high strength to weight ratio, easy to maintain and easy to install (Hence working hours can be significantly reduced). However, there are some factors that limit its regular use as- high material price and lack of design codes in GFRP in countries like India, ignorance or reluctance towards current reports, guidelines and technology currently used in publications around the world.

\section{GFRP PROPERTIES}

The basic components used to make the GFRP bar are glass-fiber filament and resin matrix, usually polyester resin. These glassfiber filaments are similar to those obtained by mixing GFRC sheets and members directly into the concrete mix. Glass-fibers intended for GFRC purposes have a special alkali-resistant coating on their surface. These strands have exceptional tensile strength and they are the load-bearing parts of the bar. Matrix or polyester resin has been introduced as a binding agent to initiate dimensional stability and hold fibers together.

The molten glass is captured by orbit and glass fibers are formed. Glass fibers are cheaper compared to other types of polymer fibers. They also have excellent insulation capabilities. Three main types of glass fibers are used in the manufacture of e-glass, $\mathrm{C}$-glass and S-glass fibers. These e-glass fibers are the most popular and widely used and are of moderate strength, electrical and acid resistance and economical. S-glass fiber has high strength applications, where high hardness and ultimate hardness are important. But these fibers are expensive. C-glass fibers find their applications where chemical stability is important. AR-glass fibers are used as crack arresters in GFRC, allowing GFRC to be applied in an alkaline environment (alkaline in concrete nature) without durable effects.

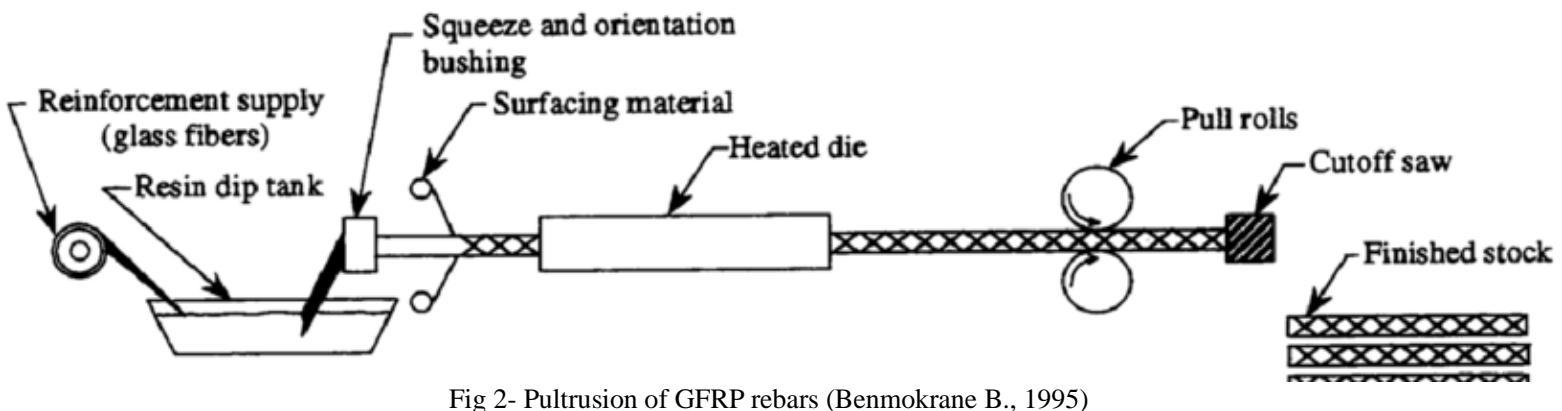

Polyester resins are used as matrix binders to make GFRP bars which have advantages as low viscosity, quick treatment time, dimensional stability, excellent chemical resistance and moderate cost. Although the physical properties of polyester are inferior to epoxy, they are relatively inexpensive (approximately 50\% of the epoxy resin content) and moderate strength, making them the preferred material for matrix binders for GFRP manufacturing.

GFRP Rebar is made by a process called the Paltration Method, which allows the production of GFRP bars of high fiber content (up to $60-80 \%$ ). The fibers used to make the bar have diameters ranging from $10 \mathrm{~m}$ to $4.5 \mathrm{~m}$ depending on the type of glass fiber. The bars are surface deformed to obtain an effective bond with the concrete. A fiber bundle dipped in resin can be wrapped around the bar before or after coming out of the heated to achieve that shape. 
1.Tensile strength- GFRP bars are anisotropic due to the origin of the fibers, which are fixed on the longitudinal axis. It has high tensile strength (500-1200 MPa) compared to steel rods (250-550 MPa). Their strength is controlled by their diameter and is inversely related to it. This is due to the phenomenon of "cut-log". The shear-log bar can explain the variation of pressures from the center to its surface. According to the experimental determination (H.V.S. Gangrao, 1991) the pressures at the surface are maximum and minimum at the middle due to the same phenomenon. GFRP bars are relatively sensitive to normal temperature fluctuations. However, at temperatures above 200 the strength decreases.

2.Compressive strength-GFRP rebars are very fragile due to the origin of the fibers and are not suitable for use in compression members. However, for most applications GFRP bars are considered more fundamental than compressive strength. The compressive strength of GFRP bars was found to be $40-60 \%$ of its tensile strength. It was found that the compressive modulus of elasticity is less than the tensile modulus of elasticity due to the intensity of the compressive stress. Although the behavior of stressed GFRP bars is straightforward to failure, it is less than the tensile modulus of steel elasticity. Typical values range from 40-55 GPa, to $210 \mathrm{GPa}$ for steel.

3.Creep and Fatigue-It has been observed and reported that the final stress caused by creep is approximately $3 \%$ of the initial elastic stress (Ehsani, 1993). Fatigue of GFRP bars is generally lower compared to steel rods.

4.Weight-Due to the fibrous origin, GFRP bars are found to be lighter than steel rods, allowing them to be easily maintained, stored and transported.

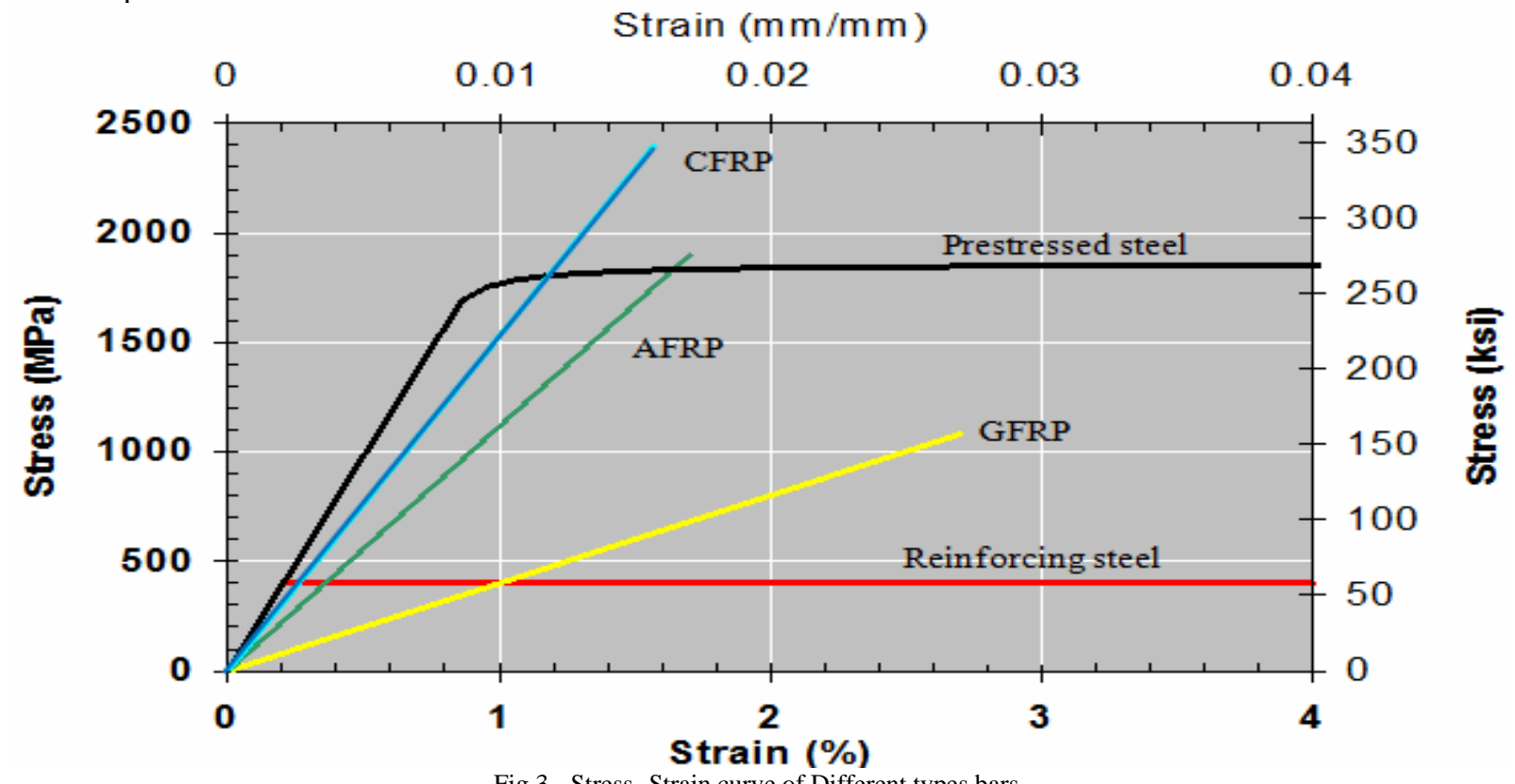

Fig 3- Stress- Strain curve of Different types bars.

TEST PROGRAM 1

To compare the nature of steel bars and GFRP bars as flexural members and the comparison of crack pattern in steel and GFRP reinforced beams. Concrete in the study should have GFRP rebar and steel reinforcement. Concrete section to be used for the study have dimensions of 100x100x500 mm(as per IS code-10086-1982 and IS code 456-2000) and the experiment should be done only with M30 concrete and beam.

\begin{tabular}{|c|c|c|}
\hline Material Characteristics & GFRP Bar & Steel Bar \\
\hline Density & $1850 \mathrm{~kg} / \mathrm{m}^{3}$ & $7850 \mathrm{kh} / \mathrm{m}^{3}$ \\
\hline Tensile strength & $750 \mathrm{Mpa}$ & $415 \mathrm{Mpa}$ \\
\hline Elastic Modulus & $50 \mathrm{Gpa}$ & $200 \mathrm{Gpa}$ \\
\hline Poisson Ratio & 0.25 & 0.30 \\
\hline Thermal Expansion & $10.8 \times 10^{-6} /{ }^{\circ} \mathrm{C}$ & $12 \times 10^{-6} /{ }^{\circ} \mathrm{C}$ \\
\hline
\end{tabular}

Table 2 - Properties of GFRP and Steel Bars. 

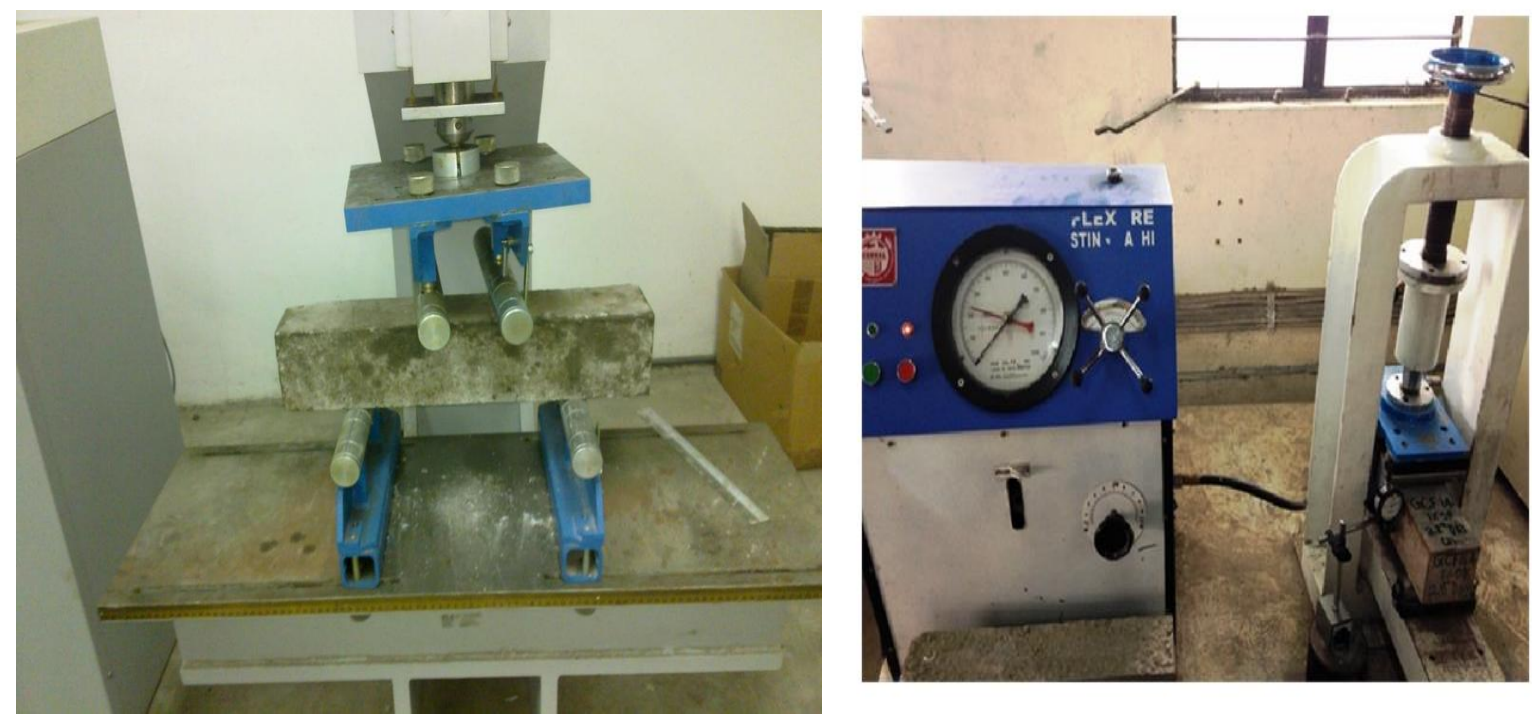

Fig 4 - Flexural Testing of GFRP and Steel Bars.

\begin{tabular}{|c|c|c|c|c|}
\hline & \multicolumn{2}{|c|}{ Ultimate Load (kn) } & \multicolumn{2}{c|}{ Ultimate Deflection (mm) } \\
\cline { 2 - 5 } & GFRP & Steel & GFRP & Steel \\
\hline Sample 1 & 65.0 & 82.0 & 14.67 & 13.87 \\
\hline Sample 2 & 67.0 & 79.0 & 14.75 & 13.92 \\
\hline Sample 3 & 64.0 & 81.0 & 14.23 & 12.90 \\
\hline Average & 65.33 & 80.66 & 14.55 & 13.56 \\
\hline
\end{tabular}

Table 3- Load and Deflection of Samples.

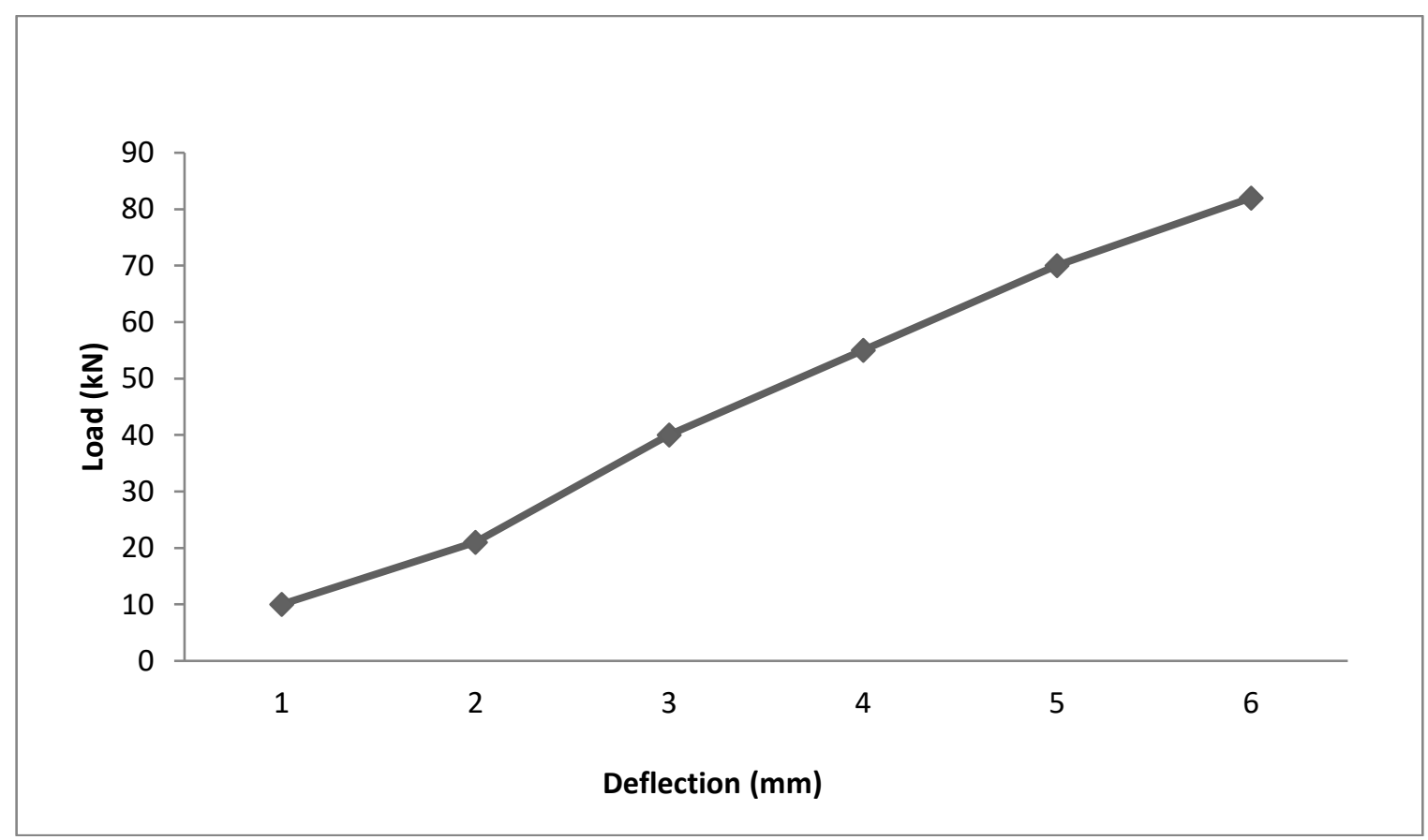

Fig 5 - Load Vs Deflection Diagram of Steel Reinforced Beam 


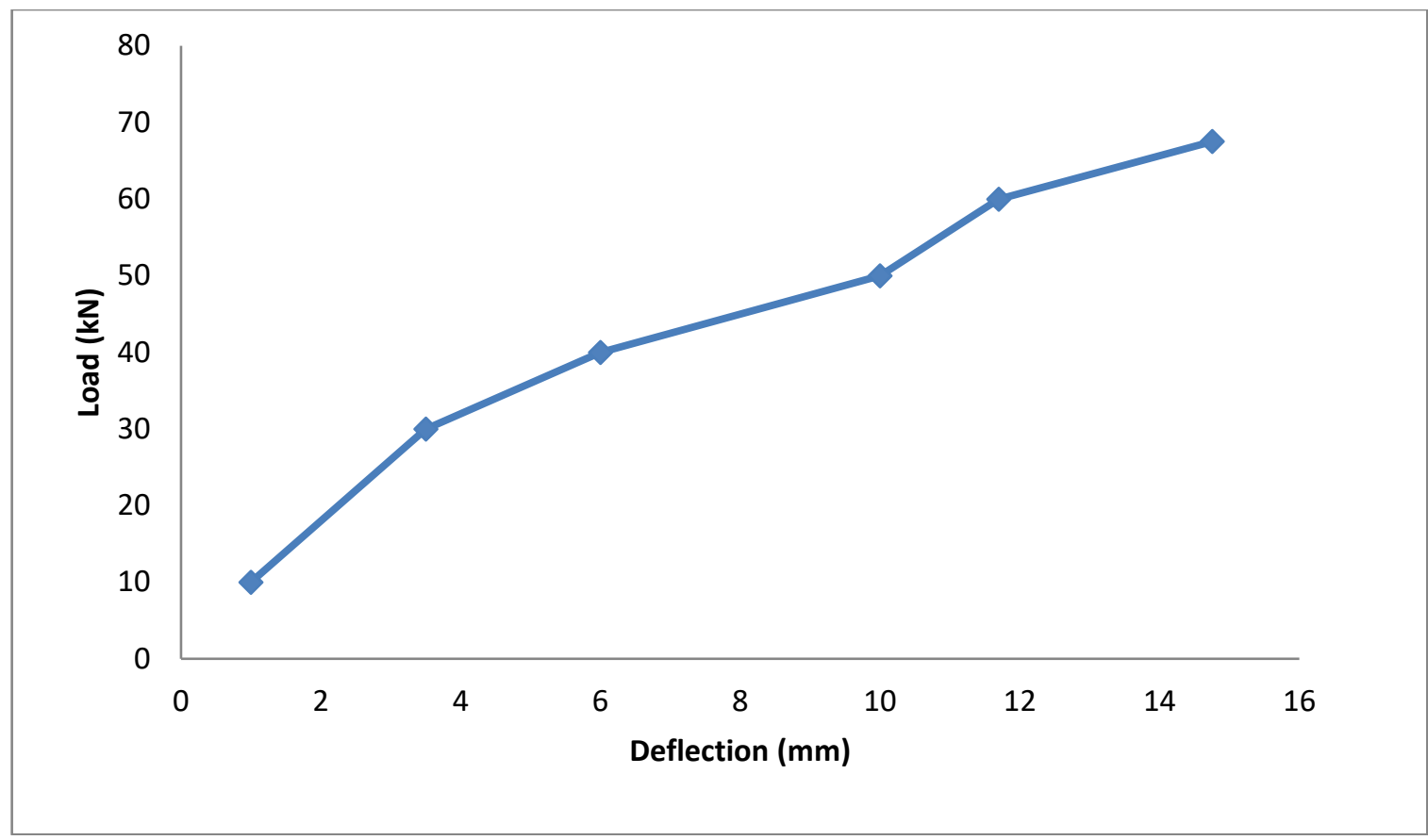

Fig 6 - Load Vs Deflection Diagram of GFRP Reinforced Beam

CRACK STUDY-

Steel bars- At the initial stage of loading, for all beams, cracks first appeared in the fixed moment zone. As the load increases, additional cracks developed in the mid span and new vertical cracks formed during the shear span. A crack pattern was observed in the steel reinforced beam that tension cracks can be observed in the center of the beam. All beams reinforced with steel rebar failed at ultimate load. The crack pattern in the steel reinforced beam showed that the initial crack occurred at the outermost side of the tension zone extends towards the center. The first crack was received at a load of $35.5 \mathrm{KN}$.

GFRP bars- In the case of GFRP reinforced concrete beams, one of the vertical cracks in the shear span is critical and extends towards loading point. The failure was mainly due to slip of rebar from the surroundings concrete. Rebar fail represents the horizontal splitting of the concrete at the level of reinforcement. GFRP reinforced beam failed due to shear. Early cleavage emerged near support loading points. The first crack was received at a load of $24.5 \mathrm{KN}$.

\section{RESULT-}

1.The ultimate load carrying capacity of steel reinforced beam is high as compared to GFRP reinforced beam of the same design capacity. The final load of the GFRP reinforced beam is $65.33 \mathrm{kN}$, the final load for the steel reinforced beam is $80.66 \mathrm{kN}$. It can be assumed that the ultimate load of the steel reinforced beam is $29 \%$ higher than the GFRP reinforced beam.

2. The ultimate deflection of the GFRP beam is greater than that of the steel reinforced beam. The received final deflection of GFRP reinforced beam is $14.55 \mathrm{~mm}$ and steel reinforced beam is $13.56 \mathrm{~mm}$. The final deflection obtained for this GFRP reinforced beam is $7.3 \%$ higher than steel reinforced beam.

3.First Crack were seen for GFRP bar is at the load of $24.5 \mathrm{kn}$ and Steel bar at $35.5 \mathrm{kn}$.

4. In steel reinforced beam, flexural failures occur, it breaks the concrete at the top of the beam. At the bottom of the beam, the yield of the steel rebar is occurred. In the case of GFRP bars, the reinforced beam is failed in shears.

\section{TEST PROGRAM 2}

The reason for conducting this research is to know the effect of various factors listed below:-

1.Evaluate the possolanic activity of waste glass dust as a partial replacement of cement and waste glass dust recycling.

2.Comparison of Waste Waste Glass Powder Cement Mortar and Conventional Cement Mortar.

3. Comparative study of waste glass dry concrete and conventional concrete.

\section{LITERATURE REVIEW}

M. Iqbal Malik and Muzafar Bashir et al (2013) studied that, Concrete samples were tested for compressive strength, split tensile, durability (water absorption) and density at 28 days of age and the results obtained were compared with normal concrete. Replacing $20 \%$ of the aggregates with waste glass will increase the compressive strength by $15 \%$ in 7 days and by $25 \%$ in 28 days. Using waste glass up to $30 \%$ instead of the best aggregates shows a $9.8 \%$ increase in compressive strength in 28 days. As the waste glass size increases, the water absorption percentage decreases. With an increase in waste glass content, the average weight of the mixture with $40 \%$ waste glass material decreases by $5 \%$, thereby reducing the weight of waste glass 
concrete. As the size of the waste glass increases, the efficiency of the concrete mix increases. The pressure strength decreases as the waste glass size increases.

N. Tamanna and N. Mohamed Sutan et al (2012) Mortar cubes of different sizes from $212 \mu \mathrm{m}, 75 \mu \mathrm{m}, 63-38 \mu \mathrm{m}$ and $38 \mu \mathrm{m}$ are made from water with cement in the ratio of 0.50 and 0.45 . The curing process maintains room temperature and relative humidity at $32^{\circ} \mathrm{C}$ and $90 \%$, respectively.

In the present study, glass powder can be used as a partial substitute for cement. Replacing with $10 \%$ cement glass powder results in higher compressive strength in 28 days than other levels. Thin-sized glass particles show better results than coarse particles.

\section{METHODOLOGY AND RESULT}

In this study we replaced the cement with glass powder and replaced it with cement concrete paste, and then examined what changes occur in the paste. We have carried out various required tests on cement and aggregates so that they give satisfactory results and after calculation we get the following composition for M30 grade concrete.

1. Cement $=420.12 \mathrm{~kg} / \mathrm{m} 3$

2. Water $=214 \mathrm{~kg} / \mathrm{m} 3$

3. Fine aggregate $=743.60 \mathrm{~kg} / \mathrm{m} 3$

4. Coarse aggregates $=1139 \mathrm{~kg} / \mathrm{m} 3$

5. Water cement ratio $=0.51$

The Test Observations are as follows-

A.Initial and Final Setting time with Standard Consistency of cement-

\begin{tabular}{|c|c|c|c|}
\hline Sample & Standard Consistency & Initial Setting Time (min) & Final Setting Time (min) \\
\hline OPC Cement & 30.0 & 36 & 400 \\
\hline Glass Replacement (10\%) & 31.5 & 41 & 415 \\
\hline Glass Replacement (20\%) & 33.0 & 58 & 435 \\
\hline Glass Replacement (30\%) & 36.25 & 65 & 450 \\
\hline Glass Replacement (40\%) & 40.0 & 70 & 460 \\
\hline
\end{tabular}

Table 4- Consistency test Results of OPC and with its Replacements

B. Compressive Strength of Cement Cubes-

\begin{tabular}{|c|c|c|}
\hline Sample & 7 Days Strength & 28 Days Strength \\
\hline OPC Cement & 22.85 & 29.55 \\
\hline Glass Replacement (10\%) & 22.50 & 29.12 \\
\hline Glass Replacement (20\%) & 22.45 & 29.05 \\
\hline Glass Replacement (30\%) & 22.63 & 28.96 \\
\hline Glass Replacement (40\%) & 18.95 & 27.62 \\
\hline
\end{tabular}

Table 5- Result of Compressive strength test of Samples at 7 and 28 Days.

\section{RESULT}

We see that the strength decreases as the percentage of glass fiber increases. Glass powder can be used as dry concrete and is very close to the required strength. When we use glass fiber, the strength is almost equal between $10 \%$ to to $30 \%$, but it decreases when it reaches to $40 \%$.

\section{CONCLUSION}

India is the fastest growing economy. Despite of all opportunities of India GFRP is difficult in civil infrastructure because it is local code controls which need to be developed as per Indian standards for GFRP consumption and subsequent production facilities. With The Asian GFRP market is plentiful, below 5\%, Growth is there for India for showing GFRP application in Civil engineering. To improve this situation, Civil Code should provide engineering and their extension programs with appropriate training on the specific characteristics of GFRPs for which engineers can design or specify them in construction. At this stage, the government needs- Industry-institute partnership to take full advantage of GFRP. The use of GFRP for retrofitting is on the rise and this is inevitable because of its potential.

\section{REFERENCES}

[1] A Kartz, N.B.A. (1998). Effect of cyclic loading and elevated tempreture on bond properties of FRP rebars. Intl. Conf. on the durability of fiber reinforced polymer (FRP) for const. and struct., 403-13. Sherbrooke, Canada.

[2] Al-Salloum, Y. A. (1996). Evaluation of service load deflection for beams reinforced by GFRP bars. Proceedings to 2nd Intl conf. on Adv. Comp. Mat. in Bridges and Struct. 165-172. Montreal, Canada: Al-Badry Ed, Canadian Society for Civil Engineering.

[3] Benmokrane B., C. O. (1995). The GFRP rebars for concrete structures. Jour. of Const. and Build. Mat., 353-364.

[4] Ehsani, M. (1993). Glass-FIbre reinforcing bars . Alt. Mat. for the reinf. and pre-stressing of conc., 35-54.

[5] Faza S., G. H. (1992). Pre- and Post-cracking deflection behviour of concrete beams reinforced with fibre reinforced plastic rebars. Proc. to 2nd Intl. conf. on Adv. Comp. Mat. in Bridges and Struct. 151-160. Montreal, Canada: Canadian Society for Civil Engineering.

[6] Fei Yan, Z. L. (2016). Bond mechanism and bond strength of GFRP bars to concrete: a review. Comp. Part B, 56-69.

[7] H.V.S. GangRao, S. F. (1991). bending and Bond behaviour and design of concrete beams reinforced with Fibre reinforced plastic rebars. West Virginia University: F rep. on Fed. Highways Admin.

[8] Hollaway L C, L. M. (1999). Strengthening of reinforced concrete structures using externally-bonded FRP composites in. Struct. and Civil Engg, W P Limited, Cambridge. 
[9] J. G. Teng, J. F. (2003). Behaviour and strength of FRP-strengthened RC structures: a state-of-the-art review. Struct. \& Build., ICE, 51-62.

[10] Kassem, C., Farghaly, A. S., \& Benmokrane, a. B. (2011). Evaluation of Flexural Behavior and Serviceability Performance of Concrete Beams Reinforced with FRP Bars. Jour. of Comp. for Const., 682-695.

[11] M.R. Ehsani, H.S. (1993). Bond of GFRP rebars to ordinary-strength concrete. Intl. symp. on f. r. p. reinf. for conc. Struct., 333-345. Vancouver, Canada.

[12] Meier U., D.M. (1993). CFRP bonded sheets. Fibre-reinforced-plastic (FRP) reinforcement for concrete structures :Properties and applications. El. Sci., The Netherlands.

[13] Meuer U. (1995). Retrofitting of Structures through external bonded CFRP sheets. Proc. of 2nd Intl. Symp. on Non-metallic (FRP) reinf. for conc. Struct. 509-516. Ghent: Taerwe L. ed.

[14] Nawy E.G., NG. (1977). Fiberglass in reinforced concrete beams and slabs. Jour. of Struct. Div. ASCE, 421-440.

[15] Head R.R.. (1996). Advanced composites in civil engineering - a critical overview at the high interest, low usuage stage of development. inforced plastic rebars. Proc. to 2nd Intl. conf. on Adv. Comp. Mat. in Bridges and Struct. 151-160 Montreal, Canada:: Can. Soc. for Civil Engg.

[16] Pleiman, L. (1987). Tension and bond pull-out tests of deformed fiber-glass rods . Marshal, Arkansas: F Rep., Vega Technologies.

[17] Saadarmanesh H., E.M. (1991). Fiber composite bars for reinforced concrete construction. Jour. of Comp. mat., 188-203.

[18] Saafi, M. (2002). Effect of fire on FRP reinforced concrete member. Comp. Struct., 11-20.

[19] Schwatrz, M. (1992). Comp. Mat. Handbook. New-York: McGraw Hill.

[20] Vicki L. Brown, C.L. (1993). FRP Reinforcing Bars in Reinforced Concrete . ACI Mat. Jour., 34-39.

[21] S.F. Husain, M. Shariq and A. Masood. GFRP bars for RC structures - A Review, Advances in Construction Materials and Structures (ACMS-2018), IIT Roorkee, Roorkee, Uttarakhand, India, March 7-8, 2018

[22] Ravikant Shrivastava, Uttamasha Gupta, U B Choubey- FRP: Research, Education and Application in India and China in Civil Engineering, International Journal of Recent Trends in Engineering, Vol. 1, No. 6, May 2009.

[23] Sudeep Vyas, Danish Khan- Feasibility Studies on Use of GFRP Rebar's as Reinforcement in Concrete, International Journal for Scientific Research \& Development| Vol. 4, Issue 07, 2016 | ISSN (online): 2321-0613

[24] Vipin George Nidhin B Parappattu, Comparative Study of GFRP Rebar and Steel Rebar used in Concrete Sections, Global Research and Development Journal for Engineering | Volume 2 | Issue 6 | May 2017 ISSN: 2455-5703.

[25] A. Almerich Chulia, P. Martin Concepcion, J.M. Molines Cano, J. Rovira Soler, NEW GFRP BARS AS INTERNAL REINFORCEMENT IN CONCRETE STRUCTURES, EUROPEAN CONFERENCE ON COMPOSITE MATERIALS, Venice, Italy, 24-28 June 2012. 